\title{
Critically ill SARS-CoV-2-infected patients are not stratified as sepsis by the qSOFA
}

\author{
Marion Ferreira ${ }^{1,2}$, Timothee Blin ${ }^{1,2}$, Nived Collercandy ${ }^{1}$, Piotr Szychowiak ${ }^{1}$, Pierre-François Dequin ${ }^{1}$, \\ Youenn Jouan ${ }^{1}$ and Antoine Guillon ${ }^{1 *}$
}

The SEPSIS-3 definitions had facilitated earlier recognition of patients at risk of developing sepsis for timely management [1]. The quickSOFA (qSOFA) has emerged as a bedside clinical score to clinically categorize a septic patient. In out-of-hospital, emergency department, or general hospital ward settings, adult patients with suspected infection are likely to have poor outcomes typical of sepsis if they have at least 2 of the qSOFA criteria: respiratory rate $\geq 22 / \mathrm{min}$, altered mentation, or systolic blood pressure $\leq 100 \mathrm{mmHg}$ [1]. This definition has been subsequently validated in the emergency department for patients with suspected infection: for qSOFA $\leq 1$ the mortality rate was $3 \%$ (95\% CI $2-5 \%$ ) vs $24 \%$ (95\% CI $18-30 \%)$ for patients with a $\mathrm{qSOFA} \geq 2$ [2]. The severe acute respiratory syndrome coronavirus-2 (SARS-CoV-2) that causes coronavirus disease 2019 (Covid-19) is a game changer. Mass ICU care and ventilatory support are needed to treat patients with Covid-19. Prompt and accurate clinical identification of SARS-CoV-2-infected patients at risk to have poor outcomes is an utmost priority. The aim of the study was to examine if the 2-point qSOFA threshold is an appropriate bedside clinical score for Covid-19 patients.

We studied patients with laboratory-confirmed Covid-19 infection who were admitted to ICU between March 14 and April 03, 2020. We defined a confirmed case of Covid-19 by a positive result on a reverse-transcriptase-polymerase-chain-reaction assay of a specimen collected on a nasopharyngeal swab or collection

\footnotetext{
*Correspondence: antoine.guillon@univ-tours.fr

${ }^{1}$ CHRU de Tours, Service de Médecine Intensive-Réanimation, CHRU Bretonneau, INSERM U1100, Centre d'Etude des Pathologies Respiratoires,

Université de Tours, 2 Bd Tonnellé, 37044 Tours, France

Full list of author information is available at the end of the article
}

of nasopharyngeal aspirate. We recorded anonymized demographic data, information on clinical symptoms or signs at presentation at emergency department, and laboratory and radiologic results during ICU admission (performed at the discretion of the treating physician). The qSOFA was calculated based on its 3 components at their worst level before ICU admission. The reuse of already recorded and anonymized data falls within the scope of the French Reference Methodology MR-005 (2016-41 law) which require neither information nor non-opposition of the included individuals. Results are in median $( \pm \mathrm{SD})$.

We identified 52 critically ill patients hospitalized in ICU with confirmed SARS-CoV-2 infection. The median age of the patients was $63 \pm 11$ years (range 28 to 78 ); $61.5 \%$ were men. The median duration of symptoms before hospital admission was $8 \pm 3.5$ days. Thirty-eight patients (73\%) received invasive mechanical ventilation; 14 patients (27\%) were discharged without the need of ventilator support (median oxygen low rate $3.5 \pm 3.6 \mathrm{~L} / \mathrm{min}$ ). For patients who received mechanical ventilation, the mean Pao2:Fio2 ratio was 146 $\pm 94: 6$ patients (16\%) had mild ARDS, 23 patients (61\%) had moderate ARDS and 9 patients (24\%) had severe ARDS [3]. Twenty-six patients $(68 \%)$ were placed in a prone position, 36 (94\%) received neuromuscular blockade. Twenty-one patients (55\%) presented hypotension requiring vasopressors; three patients needed renal-replacement therapy. The qSOFA of nonventilated patients was one or less for all the patients $(\mathrm{n}=14)$ (Fig. 1a). The qSOFA of ventilated patients was one or less for 27 patients (87\%), only 4 patients had a 2-point qSOFA, none had 3-point (Fig. 1b). All patients with $\mathrm{qSOFA} \geq 1$ scored for respiratory rate $\geq 22 / \mathrm{min}$; 


\section{a}

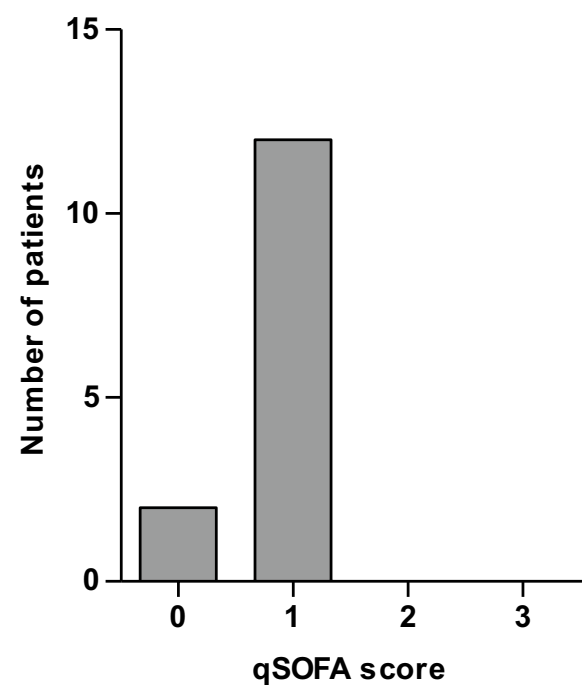

b Ventilated patients

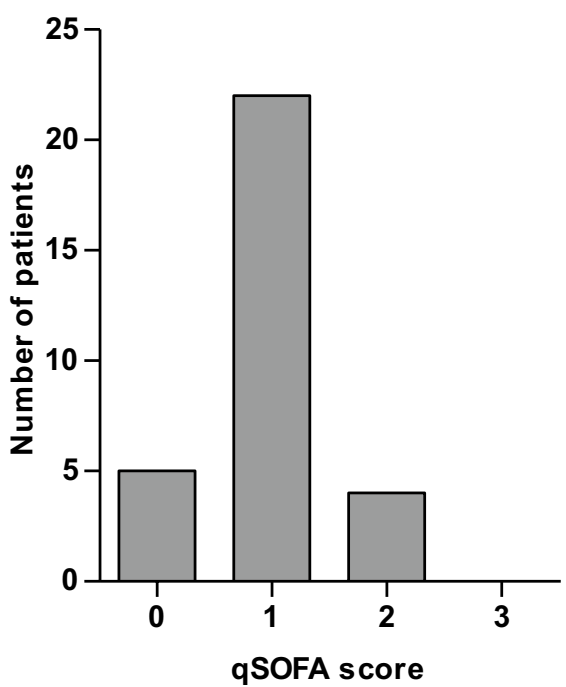

Fig. 1 Distribution of patients by qSOFA score on ICU admission among confirmed Covid-19 patients. a Non-ventilated patients. b Ventilated patients

patients with qSOFA $=2$ scored also for systolic blood pressure $\leq 100 \mathrm{mmHg}$. Seven patients had missing values to calculate the qSOFA. The case fatality rate could not be calculated as 35 patients were still hospitalized in the ICU while writing this report.

Covid-19 patients developing ARDS have a mean qSOFA score of one on ICU admission. Patients who received mechanical ventilation did not seem to have a different qSOFA than patients without ventilator support. A case fatality rate of $50 \%$ is expected among critically ill Covid-19 patients [4]. Consequently, the previous $3 \%$ mortality rate observed in patients with suspected infection and a qSOFA score $\leq 1$ is unlikely to be exact in SARS-CoV-2-infected patients [1]. We anticipate that the qSOFA is not appropriate to identify Covid-19 patient to have poor outcomes typical of sepsis.

\section{Abbreviations}

ICU: Intensive care unit; qSOFA: quickSOFA; SARS-CoV-2: Severe acute respiratory syndrome coronavirus-2.

\section{Acknowledgements}

We want to thank the medical students who volunteered to help in the management of these patients: Ariane Reignoux, Audrey Boudaille, Aurélien Proudhom, Cécile Chameret, chloé Gourdon, Clémence Lesage,Coline Curty, Coralie Pereira, Diane Iffly, Eiryann Humbert, Guillaume Marin, Hugo Baeza, Inès Havez, Jeanne Perrin, Jeremy Dervillier, Joanna Muster, Jules Corbery, Julie Collineau, Juliette Jamet, Lea Bouquin, Léo Boggiani, Lila CharpentierDusoir, Lisa Lochon, Loïse Piquemal, Marine Loty, Marion de Quillacq, Martin Deslais, Maxime Beaupied, Maxime Bobo, Maxime Delforge, Maxime Duverger, Maxime Henry, Morgane Makowski, Océane Babin de Lignac, Paul Narbonne, Paul-Marie Suret, Pierre Même, Planche Matthieu, Thomas Gosselin, Timothée Brehin, Tsiory Rakotoniaina.

\section{Authors' contributions}

MF, TB, NC, PS, PFD, YJ, AG conceived and designed the study, and were involved in drafting the manuscript. All authors read and approved the final manuscript.

\section{Funding}

The authors declare that they have no sources of funding for the research.

\section{Availability of data and materials}

Data are available from the authors upon reasonable request and with the permission of the institution.

\section{Ethics approval and consent to participate}

The reuse of already recorded and anonymized data falls within the scope of the French Reference Methodology MR-005 (2016-41 law) which require neither information nor non-opposition of the included individuals.

\section{Consent to participate}

Not applicable.

\section{Competing interests}

The authors declare that they have no conflict of interest.

\section{Author details}

${ }^{1}$ CHRU de Tours, Service de Médecine Intensive-Réanimation, CHRU Bretonneau, INSERM U1 100, Centre d'Etude des Pathologies Respiratoires, Université de Tours, 2 Bd Tonnellé, 37044 Tours, France. ${ }^{2}$ CHRU de Tours, Service de Pneumologie, INSERM U1 100, Centre d'Etude des Pathologies Respiratoires, Université de Tours, 2 Bd Tonnellé, 37044 Tours, France.

Received: 6 April 2020 Accepted: 11 April 2020

Published online: 19 April 2020

References

1. Singer M, Deutschman CS, Seymour CW, et al. The third international consensus definitions for sepsis and septic shock (Sepsis-3). JAMA. 2016;315:801-10. https://doi.org/10.1001/jama.2016.0287. 
2. Freund $Y$, Lemachatti N, Krastinova E, et al. Prognostic accuracy of sepsis-3 criteria for in-hospital mortality among patients with suspected infection presenting to the emergency department. JAMA. 2017;317:301-8. https ://doi.org/10.1001/jama.2016.20329.

3. Definition Task Force ARDS, Ranieri VM, Rubenfeld GD, et al. Acute respiratory distress syndrome: the Berlin definition. JAMA. 2012;307:2526-33. https://doi.org/10.1001/jama.2012.5669.

4. Bhatraju PK, Ghassemieh BJ, Nichols M, et al. Covid-19 in critically ill patients in the Seattle region—case series. N Engl J Med. 2020. https:// doi.org/10.1056/NEJMoa2004500.

\section{Publisher's Note}

Springer Nature remains neutral with regard to jurisdictional claims in published maps and institutional affiliations.

\section{Submit your manuscript to a SpringerOpen ${ }^{\circ}$ journal and benefit from:}

- Convenient online submission

- Rigorous peer review

- Open access: articles freely available online

- High visibility within the field

- Retaining the copyright to your article

Submit your next manuscript at $\boldsymbol{\nabla}$ springeropen.com 